\title{
Puppy Strangle in Labrador Puppy- A Case Report
}

\author{
Rajkumar Patel ${ }^{\text {** }}$, Vijay Trivedi ${ }^{2}$ and Rajesh Patel $^{3}$ \\ ${ }^{1}$ Veterinary Officer Integrated Tribal Development Project, Khedbrahma Gujarat, India \\ ${ }^{2}$ Veterinary Officer Society of Prevention of Cruelty to Animals (SPCA), Bhuj, Gujarat, India \\ ${ }^{3}$ Veterinary Officer Dr. Shyama Prasad Mukharjee Municipal Zoo, Surat, Gujarat, India \\ *Corresponding author
}

\section{A B S T R A C T}

\begin{tabular}{|l|}
\hline K e y w o r d s \\
$\begin{array}{l}\text { Corticosteroid, } \\
\text { Juvenile cellulitis, } \\
\text { Pyogranulomatous } \\
\text { lesion }\end{array}$ \\
\hline Article Info \\
\hline $\begin{array}{l}\text { Accepted: } \\
\text { 18 November } 2020 \\
\text { Available Online: } \\
\text { 10 December } 2020\end{array}$ \\
\hline
\end{tabular}

\section{Keywords}

Corticosteroid Juvenile cellulitis, Pyogranulomatous

\section{Introduction}

Puppy Strangle (Canine Juvenile cellulitis) is a rare granulomatous and pustular disorder of the face, pinnae, and submandibular lymph nodes, usually, puppies are affected between the ages of 3 weeks and 4 months (Kumar $e t$ al., 2013). Approximately 50\% of affected puppies are lethargic and depressed (Scott et al., 2001, Mason and Jones, 1989) and the clinical signs are often rapidly progressive within $24 \mathrm{hr}$ to $48 \mathrm{hr}$. and characterized by painful swelling of the muzzle, lips, and eyelids and Submandibular lymphadenopathy occur. Otitis externa is common, and pinnae are frequently thickened and edematous. Nodules over the trunk, preputial, and perineal areas as well as sterile suppurative arthritis manifesting as joint pain, have been reported in a small number of cases (David, 2015).

The disease has a heritable component as it has been documented more frequently in certain breeds like Golden Retrievers, Labrador Retriever, Siberian Husky, Miniature Poodle, Lhasa Apso, Dachshunds, Gordon Setters, and Weimaraners (Scott et al., 2001).It has been reported that occurrence of canine juvenile cellulitis may be related to 
an immunological response to modified live canine distemper virus, adenovirus- 2 and parainfluenza vaccine (Reimann et al., 1989).

\section{History, Clinical examination, and diagnosis}

A 56 days old Labrador retriever weighing 2 $\mathrm{kg}$ was presented with a history of forelimb lameness, fever, anorexia, sudden onset of swelling of muzzle, eyelids, and face (Fig-1). nodules on the bilateral neck and forelimb (Fig-2), bilateral ear discharge for 10 days after the administration of primary vaccination. The case did not respond to antibiotic therapy. Clinical examination of dog revealed erythema, crusted nodular lesions on muzzle, eyelids face and forelimb, swelling of sub-mandibular lymph nodes. Based on typical clinical findings and response to therapy, the disease was diagnosed as juvenile cellulitis and clinical treatment undertaken. Condition must be differential diagnosed with demodicosis, deep pyoderma, adverse reaction to drug, dermatophytosis and pemphigus foliaceus (Dubey and Sarkar, 2013).

\section{Treatment and discussion}

The present case was successfully managed with an oral Prednisolone @ 2mg/kg once daily for 14 days followed by oral prednisolone @ 1mg/kg every $24 \mathrm{hr}$ for 7 days. Syrup. Vita best derm (containing multivitamin) orally @ 5ml every 24hr for 15 days once-daily also prescribed. On the 2 nd day, significant improvement in skin lesions and pain greatly improved following immunosuppressive corticosteroid therapy, and the animal recovered in 14 days.

Canine juvenile cellulitis is cutaneous manifestation of a systemic illness characterized by erythema, crusted nodular lesions on muzzle, eyelids, face, pinna and swelling of sub-mandibular lymph nodes usually affects one individual in a litter and has an autoimmune cause with a hereditary component.

Fig.1 Marked inflammation noticed over the periocular, muzzle, face

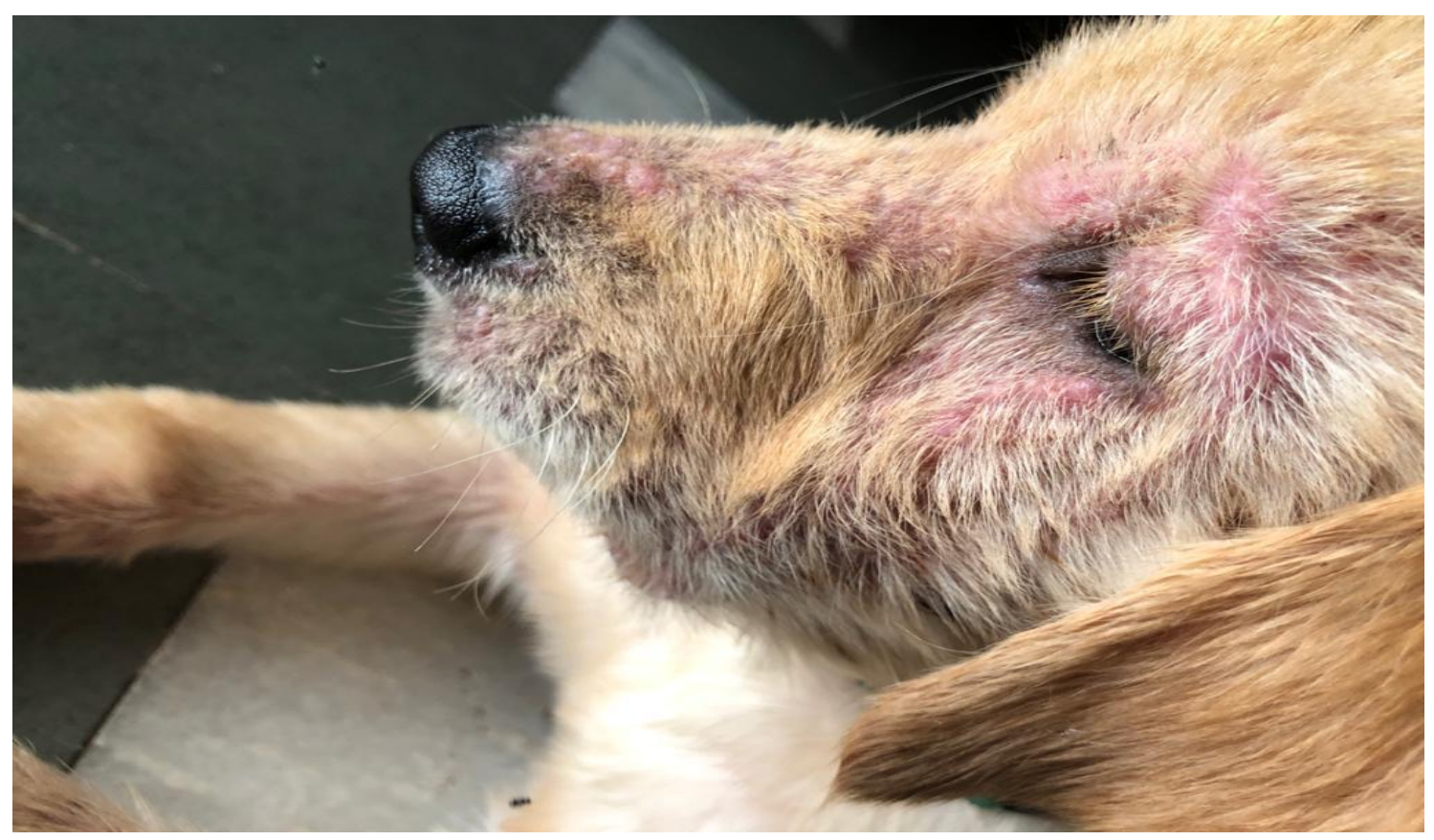


Fig.2 Focal alopecia, erythema, crusted nodular lesions over the muzzle, eyelids, face, and forelimb

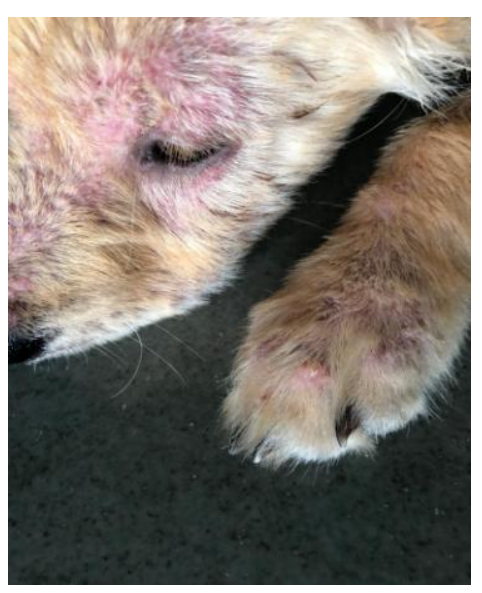

The disease occurs more frequently in Pointers, Golden Retrievers, Dachshunds, Gordon Setters, and Beagles. In the present case, the general clinical signs of lethargy, pyrexia, anorexia, and the sudden swelling of the face and muzzle were noticed first followed by the development of raised bumps and pustules over the face, muzzle, and ears. Over time, these pustules may rupture, and crust over the affected area seen was similar to juvenile cellulitis. Affected skin is often painful but not pruritic.

The noticeable dermatological signs recorded in this case were in accordance with earlier reports made by (Krishna Nath et al., 2020). although, some authors also observed pustule and crusting over the abdomen, thorax, vulva, prepuce, or anus which is absent in this case. The standard treatment of puppy strangles involves an immunosuppressive dose of glucocorticoid (David, 2015) furthermore, the puppy responded well to immunosuppressive therapy suggesting an etiology related to immune dysfunction. Tapering of glucocorticoid dose must be done carefully to avoid quick relapse of signs. If cytology indicates secondary bacterial infection, suitable antibiotics can be administered. However, in our case animal already treated by a local veterinarian, and the case does not respond to antibiotics so not used. The presence of puppy strangles lesions is highly characteristic in appearance and taken with the age of onset and the fact that most of the litter are unaffected provides a clear clinical clue (Ihrke, 2008). These clinical clues also are valuable when creating a differential diagnosis list and treatment adopted would be advantageous in a field setting for veterinarians to form an early conclusion of juvenile cellulitis.

\section{References}

David, G. 2015. Canine juvenile cellulitis (Juvenile pyoderma, puppy strangles).Veterinary practice $P: \quad 37$, May.

Dubey, P., Sarkar, S. 2013. Therapeutic management of juvenile cellulitis in Labradorpup. Intas Polivet, 14:232-233.

Ihrke, P.2008. Clinical markers of selected dermatoses: visual clues. In: 33rd World Small Animal Veterinary Association World Congress Proceedings. Dublin, Ireland: Veterinary Information Network.

Kumar, A.A., Pillai, U.N., Aipe, A.A. 2013. Clinical management of juvenile 
cellulitisin adachshund pup. Scott, D.W., Miller, W.T., Griffin, C.E. 2001. IntasPolivet, 14:234-235. Small Animal Dermatology, 6 ed.

Mason, I.S., Jones, J. 1989. Juvenile cellulitis in Gordon setters. Vet Rec., 124:642.

Reimann, K.A., Evans, M.G., Chalifoux, L.V., Turner, S., DeBoer, D.J., King, N.W., Letvin, $\quad$ N.L. 1989. Clinicopathologic characterization of canine juvenile cellulitis. Veterinary Toronto: WB Saunders, pp.1163-1167. Unny, N.M., Nath, M.K., Pillai, U.N. 2020. Juvenile Cellulitis in a Dachshund Puppy-A Case Report. The Indian Journal of Veterinary Sciences and Biotechnology, 15(04), pp.88-89. Pathology, 26(6), pp.499-504.

\section{How to cite this article:}

Rajkumar Patel, Vijay Trivedi and Rajesh Patel. 2020. Puppy Strangle in Labrador Puppy- A Case Report. Int.J.Curr.Microbiol.App.Sci. 9(12): 2798-2801.

doi: https://doi.org/10.20546/ijcmas.2020.912.334 